\title{
Energy resources for transport: political apathy and neglect - an Australian experience
}

\author{
R. G. Boothroyd \\ Retired Chartered Engineer, Queensland, Australia
}

\begin{abstract}
Australia is especially vulnerable to transport problems arising from a likely reduction in the availability of liquid fuels in the near future. This applies to the servicing of our large congested capital cities and, in different ways, to accommodating the basic needs of our widely dispersed rural communities. Despite recent publicity, this vulnerability has been ignored in political and public discussion. Technologies/management systems, which may be applicable in ameliorating this impending problem are being reviewed. These approaches are illustrated in an example intended to help safeguard the economies of Queensland and New South Wales. The importance of prior planning for an uncertain future is demonstrated.

Keywords: sustainability, climate change, peak oil, policy options, oil supplies, risk management.
\end{abstract}

\section{Introduction}

Few people would deny that we live in volatile and uncertain times. Casti [1] has reviewed eleven areas, which could bring disaster to our world. We can, at least, hope and pray that ten of these will never happen but the "drying up of world oil supplies" [1] is inevitable [2-7] and it would be folly not to plan for this event. Only 4 scenarios causing oil shortage are considered [1] from an enormous number of widely-varying possibilities.

The best that we can hope for in our uncertain future is a slow reduction in petroleum resources forcing us to change our habits. Looking back on recent history, it is much more likely that a sudden and unexpected crisis will cause worldwide economic disruption. The powerful "law of supply and demand" has an exaggerated effect for a vital resource, which would cause fuel prices to 
suddenly increase beyond our control. Tackling this future problem will vary in different nations but there are many common features in the way we can ameliorate these problems.

Casti [1] also draws attention to the extreme fragility of modern economies because they are geared to high efficiency. Cheap transport is an important factor because this allows manufacturers to maintain minimum stocks of imported components. Supermarket shelves also usually become depleted in a couple of days from panic buying after a crisis emerges. The same experience was found when recent floods in Australia interrupted road transport.

\section{Climate change or peak oil?}

In an authoritative lecture, Dunlop [8] has demonstrated that climate change and fossil fuel reserves are intimately related [2] and both are a threat. Fig. 1 from slide (6) in his lecture [8] illustrates the danger we are in from runaway global warming [9], mainly from thermal disintegration of methane clathrate and other natural methane deposits. Natural gas is more than 100 times as effective as a GHG compared with $\mathrm{CO}_{2}$ when first released. Some self-interested corporations have blatantly misused the much lower 100 year average value in their calculations. The World's climate is one of the most complicated control systems known to mankind involving many interacting positive and negative feedback loops. Attention is drawn in fig. 1 to natural warming and ice-ages in the last 500 thousand years and the inhospitable climate 50 million years ago.

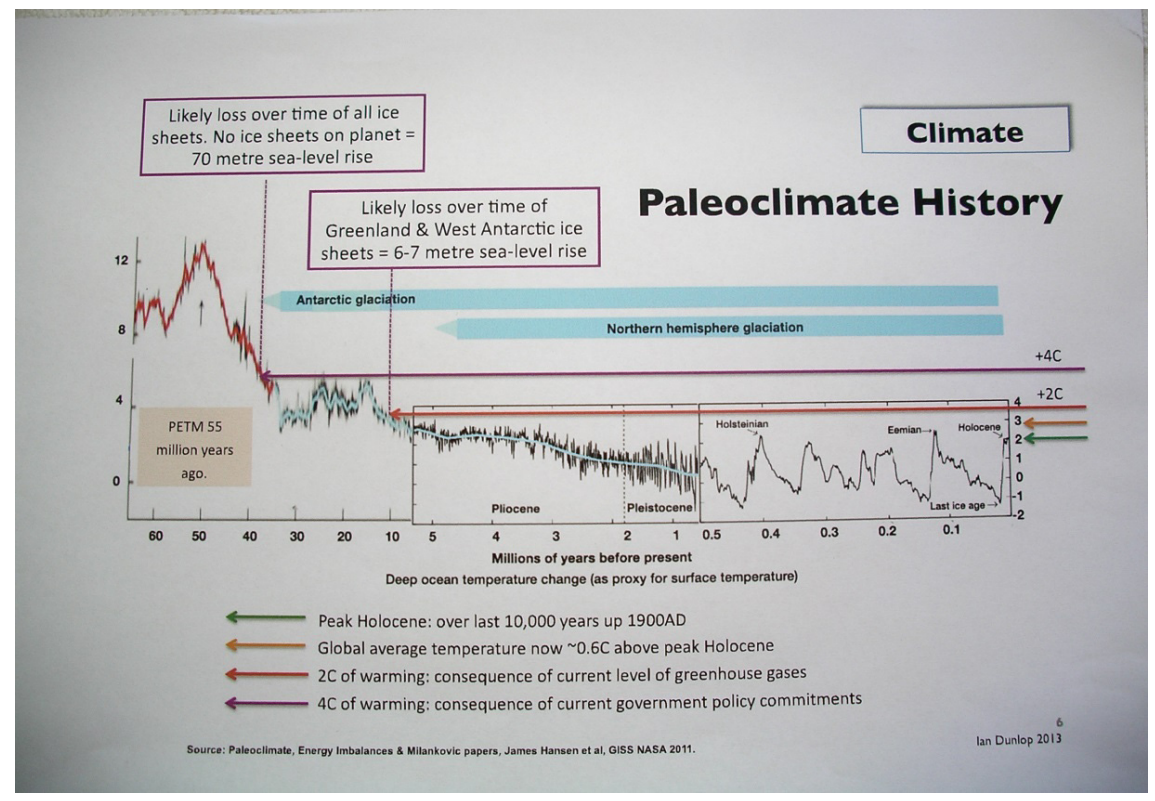

Figure 1: Effects of global warming. 
Dunlop concluded that at least $60 \%$, and perhaps even as much as $80 \%$, of fossil fuel deposits must be left undisturbed if we are to avoid a climatic disaster, which is impossible to control.

Recent improvements in deep-drilling technology may give us a (ten year? [3]) respite in the need to move over completely to sustainable energy systems. It is an interesting speculation to suggest that recent economic recovery in the United States originates mainly from shale oil and gas extraction. Is this our last chance to stabilise our civilisation? Our western-style economies are critically dependant on low transport costs. Most affluent economies also now live beyond their means as world debt increases. It seems that a large part of our task is to keep transport costs within reasonable bounds and, at the same time, restrain ourselves from unnecessary waste and extravagance.

\section{Relevant literature and expertise}

ASPO (Association for the Study of Peak Oil and Gas) [10] is an international body with a strong Australian branch [11]. These websites contain listings of peer-reviewed papers, books, other documents and statistics.

Another well-established international body of relevance to this paper is CASSE (Centre for the Advancement of the Steady State Economy) [12].

Business interests [13] illustrate the complexity of the problems we face from Peak Oil.

\section{Suggested methodology in safeguarding a nation's economy}

The examination in the present paper suggests an approach based on three consecutive considerations.

* Look for advantageous features, which may be exploited. These may be natural or man-made.

* Integrate plans with other impending and associated problems. Climate control and survival of existing business infrastructure in all areas of commercial activity are examples.

* In any nation, different areas of concern may need a different approach. In many cases this applies when considering urban vs. rural needs.

\section{Review of available technologies}

Although they are more at risk of hardship, rural communities have a wider range of available methods to overcome problems compared to those available to city populations [5].

This paper is confined to those technologies, which can be applied at short notice. Promising future methods of generating sustainable fuels, which are still in the research/development stage, are excluded. One such example is derivation of liquid fuels from algae [14, 15]. These fuels are still uncompetitive commercially but if success is achieved, particularly in using cheaper racecourse pond techniques [14], then this situation may change policy. 


\subsection{The hydrogen economy and wind energy}

Generating hydrogen from fossil fuels has been dismissed as uneconomic [16].

In the Australian rural context an electric car [17, pp. 30-77] using electrolytic generation of hydrogen coupled with hydride storage [18] and fuel cell drive has some attraction for short-distance commuting to local towns. Regenerative braking [19] on all four wheels would normally be incorporated to extend the vehicle's range.

On rural properties small windmills, and even older photovoltaic arrays, which have become unreliable, can be adapted easily for electrolysis to generate hydrogen [20]. Such systems could also benefit from a small high speed flywheel system [21] to store surplus energy if these were made available at an acceptable price. These flywheels could be used up to their maximum rated speed safely by burying them, perhaps even without a concrete casing. Burial is a common safety practice when using very large and highly-stressed high-speed flywheels for large-scale electrical power stabilisation/storage schemes.

Storage and release of hydrogen in many materials has been studied in depth for many years [18] because this is the most promising way of using hydrogen in a vehicle. Extensive research work continues in this area but electric vehicles still command only a small share of the vehicle market.

An alternative and cheaper system of providing transport for rural communities is the suitcase scooter, originally intended for urban dwellers [22]. This is discussed in section 6.3 because a windmill-energised high-speed flywheel system seems much more likely to be used to charge lithium-ion batteries for suitcase scooters kept on a rural property.

\subsection{Biofuel systems}

Encouragement of biofuel production, without taxation, on agricultural properties is essential policy if Australian farming is to maintain a secure future. The penalty of reduced area for food production is a price, which has to be accepted. Production of biodiesel and SVO (straight vegetable oil) is already taking place on some properties. Ref. [23] is a useful source of information for oil-seed plant varieties, which may be suitable in Eastern Australia.

Most modern agricultural machines in use have high-efficiency, common-rail, diesel engines which limits them to using biodiesel. Some older machines may be suited to SVO conversion although there is a risk of higher maintenance costs. SVO is better suited to old-fashioned indirect injection diesel engines with prechambers [24]. There is a perceived market for agricultural machines to run on SVO because it is easier, and safer, to make than biodiesel on the farm.

Ethanol is of little significance, not just because more than $95 \%$ of farm machinery is diesel-powered, but because ethanol cannot alleviate fuel shortage problems, at short notice, even in a rural setting. It is impractical to refine ethanol to necessary standards on a farm because ethanol's inevitable water content from production cannot be reduced sufficiently [25]. For a different reason, the same conclusion applies in an urban setting where commerciallyavailable ethanol would be available. This arises because it is reasonable to 
expect commercially-available ethanol to follow petroleum prices closely in the event of a fuel crisis. The lead time to enlarge commercial ethanol production capacity is also far too long to be useful when we are faced with a sudden emergency.

\subsection{Small diesel engines}

Whereas small petrol engines are available for such applications as chain saws and other garden tools, no such lightweight air-cooled alternatives are available using diesel. This is an area of technology, which has received almost no attention. Yet diesel fuels can be made locally on a small scale whereas ethanol and petroleum cannot.

It is not commonly realised that the achievable power/ weight ratio of a small diesel engine should increase as its designed size decreases. This advantage arises from the lesser stress problems in designing small machines. Although, strictly speaking, such a comparison is unjustified, 50 years ago the lightest engines available for model aircraft were diesels running on dimethyl ether [7]. However these tiny engines seem to have been superseded today by small petrol engines with elaborate electronic controls. Very small diesels, like larger diesels, are also more efficient than petrol engines of comparable size but they may well require a different fuel specification and even a different pre-chamber design compared with larger engines. This is seen as a commercial area with potential, which has not yet been realised.

\subsection{Flywheels}

Huge investment in research into developing better chemical energy storage (batteries) has yielded only modest results [17, pp. 30-77]. As an alternative to chemical batteries, energy-storing high-speed flywheels were used in buses as early as 1953, but with uninspiring results. Like many other good ideas, commercial application was attempted far too early before there was adequate supporting technological expertise [26, 27]. Expertise often takes years to develop but, for flywheels, it has now caught up to make these devices much more attractive [26].

Schematic fig. 2 shows the essentials of a flywheel prime-mover. They now use sophisticated magnetic bearings both for levitation and position control thus avoiding all physical contact as they spin in a near vacuum A control system adjusts the magnetic field in these bearings continuously, an internal motor/generator allows very fast rates of energy transfer to and from the flywheel, far in excess of that achievable in a chemical battery $[17, \mathrm{p}$. 6]. In a vehicle application flywheels would be expected to be gimbal-mounted. Recent opinion, however, suggests that gimbal-mounting may not always be necessary for many vehicles.

\subsection{CTL (Coal to Liquid Fuel Conversion)}

Australia has vast coal reserves but it appears to be uneconomical to invest in CTL in an economy, which is functioning normally. Even a "Sasol type" facility for military security is of questionable value. 
It is important to accept that today's large consumption rate of petroleum is unsustainable and using coal reserves for conversion to liquid fuels is not a viable alternative [28].

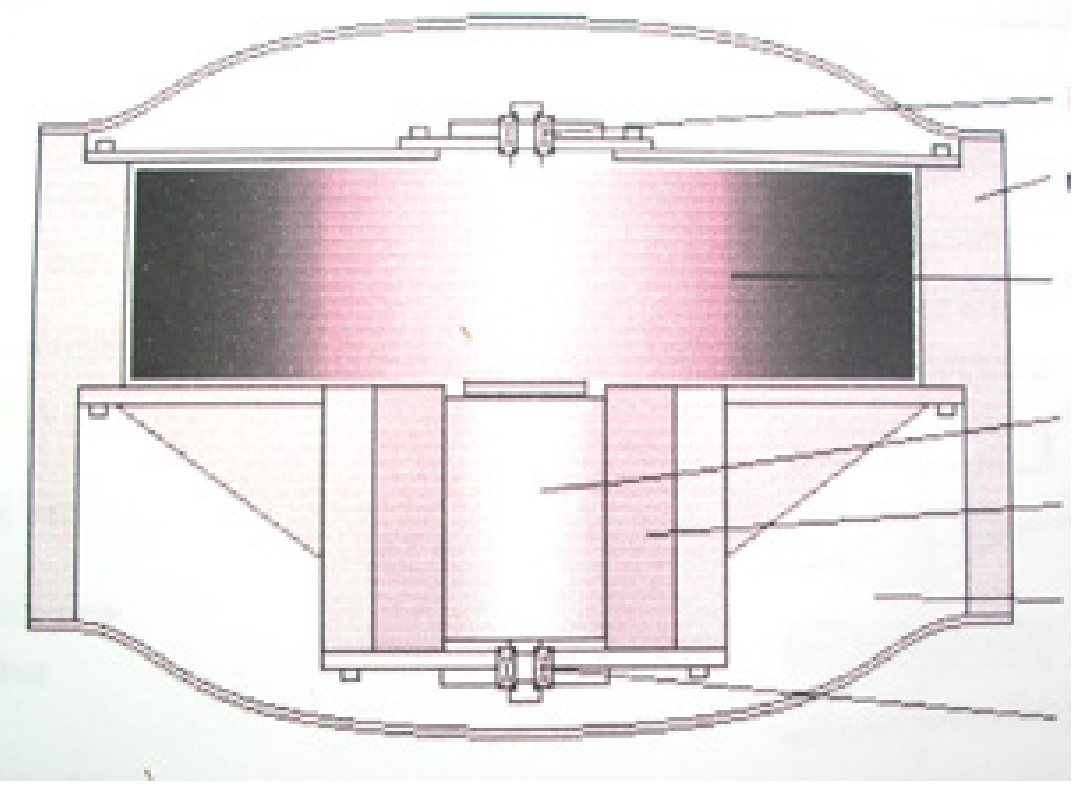

Figure 2: Schematic view of modern flywheel. The lines on the right indicate the main parts. In descending order they are: upper bearing which is shown schematically as mechanical, whereas it is magnetic and larger than shown with its control system; strongly constructed housing; integrated motor/generator (the part indicated is the rotor attached to the flywheel); stator shown without power input/output connections; evacuated housing space; lower bearing which is shown schematically as mechanical but it is a compound magnetic type with associated control gear. Adapted from ref. [26].

\section{Illustrative example: safeguarding the economies of Queensland and New South Wales (NSW)}

\subsection{Exploiting the present situation}

Fig. 3 shows existing CSG wells in Queensland and NSW. In an emergency situation it seems reasonable to tap into these resources to provide temporary fuelling points for CNG-engined vehicles such as trucks and buses. Both government and privately-owned CSG companies share a common concern in avoiding disruption of the national economy. CSG companies use diesel fuel for most of their equipment and almost inevitably the limited strategic reserves in a 
crisis would be allocated by Federal Government, in the first instance, for military purposes. CSG companies would need concessions in the allocation of limited diesel supplies in order to continue their business. Environmental requirements relating to using unprocessed $\mathrm{CNG}$ can be suspended in an emergency situation. Such an agreement with CSG companies would allow essential supply services for rural areas to continue along the corridors indicated by the data in fig. 3 .

It is an ironic twist of fate that CSG development, which has been criticised so severely and with much justification, in both the United States and Australia, for its damage to agricultural land and water quality in particular, seems likely to become the source of our salvation.

Queensland's coastal areas lack CSG development but have the alternative advantage of an electrified railway line from Brisbane to Mackay. This would be vital in maintaining essential services to coastal regions. The extension of this electrification northwards to include Townsville and terminating in Cairns is seen as a priority issue for national security. In a limited way, CNG could also be accessed from major pipelines intended to take gas to the coast for liquefaction and export.

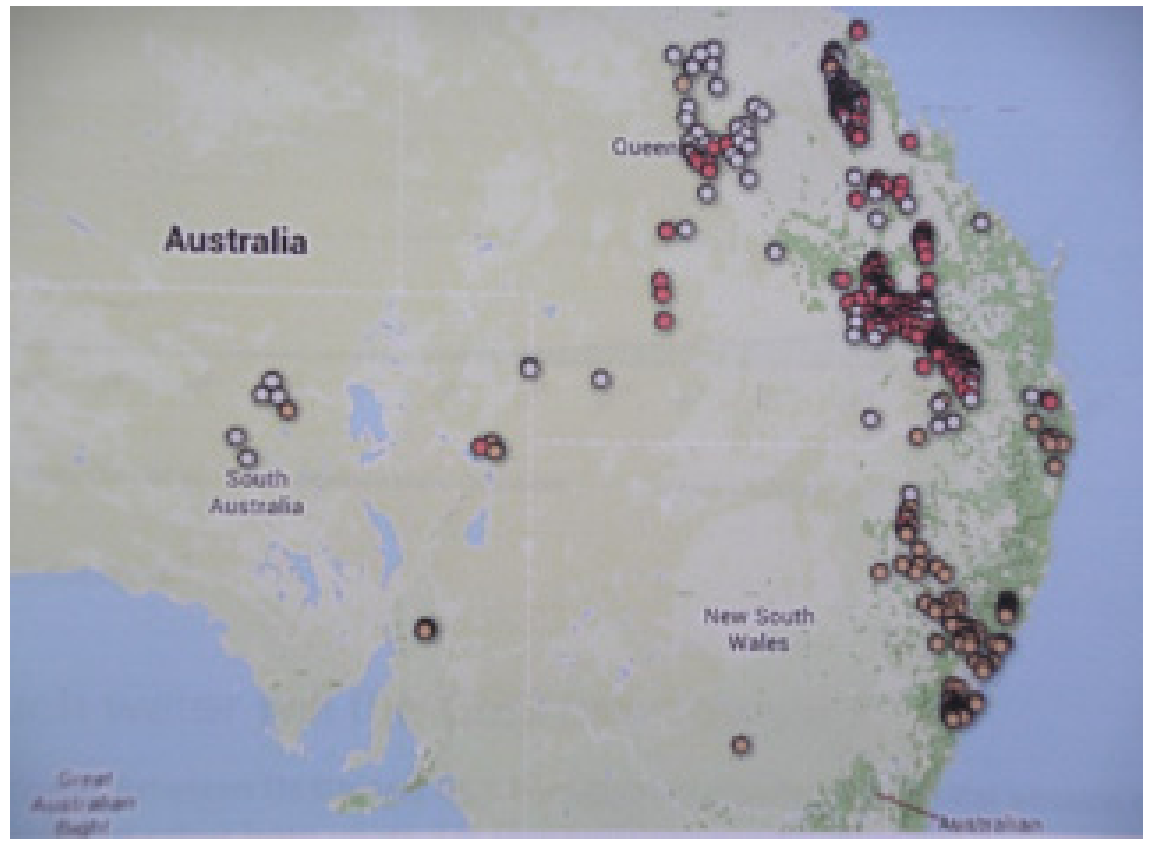

Figure 3: Location of CSG wells in Australia (accumulated government data as at 2011). It is expected that there will be 40,000 of these in Queensland alone at full production with a similar number in NSW. Each one of these is potentially a fuelling source but in practice these fuelling points would be at hubs in the gas collection network. 
The overall conclusion is that good organisation and prior planning can maintain essential services for these two important states on the Australian Eastern seaboard.

\subsection{Expected long term developments}

It seems reasonable to predict that two areas of transport would contract markedly in an extended international fuel crisis situation.

1) Domestic air services would be curtailed because of increased fuel costs, if not from imposed fuel rationing.

2) Much the same conclusion can be expected for intercity transport by private car.

Two other areas would then expand to fill the gaps arising from (1) and (2).

3) More frequent use of electronic communication such as teleconferencing.

4) Expanded intercity bus services using CSG gas. The only way to provide this facility at short notice in an emergency is to deploy citybased CNG-fuelled urban buses for this task. This is part of the main stimulus for the project suggested in sections 6.3-6.4. A limited contribution from other existing forms of CNG powered vehicles also merits examination. Conversion of diesel trucks to $\mathrm{CNG}$ is subject to workshop delays but would become necessary in an expected prolonged fuel crisis.

\subsection{Planning for a future crisis}

Planning may seem to be a difficult area because we cannot predict difficulties in the future with any precision. Nevertheless there are some rational precautions that we should undertake. One example is to develop an urban bus system, which will always be independent of fossil fuels such as one using solar-generated electricity $[29,30]$.

Australian cities have already taken significant steps to reduce harmful diesel particulate emissions by using CNG powered buses. However recent research has shown that CNG buses have significant emissions when accelerating from bus stops [31]. In this respect flywheel-energised buses are far superior environmentally for city use.

As mentioned above these CNG-powered buses are also attractive for deployment in rural areas in the event of a sudden fuel crisis. Thus these CNG vehicles offer opportunities for selling at a premium price for anticipated expansion of rural public transport in a fossil-fuel starved world. They also offer opportunities for relatively easy conversion to suit their new rural role.

These redeployed buses could be progressively refurbished, when public demand allows this, for their new role. For example limitations on fuel supplies suggest that they should carry parcels and other light freight, perhaps even packaged food items Also with regard to passenger convenience, equipping these buses with on board storage for 'suitcase-scooters' [22] is attractive for shopping where there is an expectation of further travel on arrival at the bus 
terminal. Some travellers would opt for taking their personal transport (with foldable trailers [22]) with them on the bus. Suitcase-scooters were originally envisaged only as a solution for urban transport [22] but they are of interest in a rural setting in a fuel crisis. However many travellers would prefer to leave their personal transport scooters at the bus stop and carry their own shopping if their destination is only to a large shopping complex. These alternatives can be satisfied easily once local requirements make themselves plain.

\subsection{Replacing city public transport vehicles which have been deployed to rural areas}

It is arguable that all future urban buses should be powered by flywheels. This is to eliminate all future dependence on fossil fuels. Details of this long-term planning proposal are given in Appendix 2. A brief outline of the suggestion is as follows:

An electrically-powered bus using stored flywheel energy generated by solar power is even cleaner than a CNG powered vehicle. Buses used for city transport also have an exploitable advantage in that they stop frequently for passengers. Flywheels can be recharged quickly [26]. These conditions imply that these flywheels can also run below their maximum safe speed and yet have sufficient stored "battery" energy to get to the next stop with ample reserve energy for the charging process to be repeated. This overcomes one of the main objections to using high speed flywheels, namely concerns for public safety. Modern high speed flywheels of filament construction have a good record [32] in respect of possible disintegration of the wheel. Also a bus is subject to daily inspections at the depot and, if there is any suspicion that a flywheel is faulty, exchanging with a complete refurbished flywheel assembly would be straightforward. Also the bus drivers in Brisbane, for example, seem to have no trouble in placing their bus within $5 \mathrm{~cm}$ of other vehicles and obstacles. The charging system described in Appendix 2 only requires driver placement accuracy of $+/-15 \mathrm{~cm}$.

It is suggested that the Australian Federal Government should seek a contract to develop use of this technology as a matter of urgency in conjunction with at least one capital city transport authority.

\section{Conclusions}

Specific conclusions are mentioned in this paper where it is felt that they are appropriate. However it is often felt inappropriate to come to general conclusions in this technological study, which is still at an early stage.

Nevertheless it is of concern that planning for long-term sustainability in any area is not a topic receiving adequate public discussion despite the publicity given by many well-qualified experts such as in refs [2-12].

Perhaps this stems from a weakness in our democratic society? Are our hardpressed political leaders avoiding troublesome, complicated or frightening issues whenever they can?

Alternatively is the public becoming subjected to information overload or perhaps even systematic brainwashing? Brainwashing seems evident enough 
from a near $30 \%$ of our commercial TV programmes now being given over to innumerable repeats of mind-numbing advertisements. $70 \%$ of Australian newspapers are owned by an influential expatriate and they even refused to accept advertisements with alternative political views in the run up to our recent federal election. The evidence for organised manipulative control of our critical abilities is surprisingly strong.

Perhaps our problem lies with the general public who may prefer to close their eyes to a situation, which appears to be insurmountable, and outside their control? In an interesting recent psychological study [33], public perception of Peak Oil has been likened to a person facing a terminal illness. The reality sick people have to face is to accept the best available medical treatment, even if it is painful, because this is their best hope of survival.

This comparison seems to summarise the general conclusion that, painful as it may seem, improving our public transport is the way we need to go [34] and personal transport can then become inexpensive and basic. There seems little doubt that the future will force us to give up the extravagant and unsustainable methods we use today.

\section{Appendix 1: nomenclature - acronyms}

CNG Compressed natural gas.

CSG Coal seam gas.

FES Flywheel energy storage (sometimes FFES is used).

GHG Greenhouse gas.

RIRDC Rural industries research and development corporation (Australia).

SVO Straight vegetable oil. This is unprocessed oil used in some older diesel engines with minimum modification. Its viscosity normally has to be reduced by moderate heating to give it characteristics comparable to straight diesel or biodiesel.

\section{Appendix 2: flywheel energising details for urban buses}

Fig 4 shows both a plan view and an 'across the road elevation' detail for an electric charging system built within the road at a bus stop. This is suggested as cheaper, less obtrusive and more convenient than the alternative overhead-cable charging system first used on flywheel powered buses. On the right hand side of fig. 4, a matching moveable electric contact system located on the underside of the bus is also shown.

Normally all that is visible to the general public is a strong steel cover plate about $1000 \mathrm{~mm}$ wide $\times 250 \mathrm{~mm}$ long. This plate is located on a slight rise on the road surface.

When the bus approaches a stop and covers the $1000 \times 250 \mathrm{~mm}$ plate, a coded radio signal from the bus energises a lifting mechanism for the plate, which rises on its hinge as shown in fig. 4 exposing a pair of contacts. Simultaneously a matching pair of contacts on the bus moves downward from its protective cavity in the bus chassis and then moves forward to make contact with the terminals in 
the road. A low current control circuit checks the connection and then energises the relay to commence power supply to the flywheel.

The flywheel speeds up to the speed dictated by the data in the bus computerised control system. The speed depends on the data fed into the bus computer specifying the route used and the stop at which the bus is stationary. The electrical connections then retract to their non-working conditions and an interlock allows the bus to be driven to the next stop. All this is automatic and normally takes only a few seconds while passengers disembark and enter the bus. All that is apparent to the driver is a light and audio signal on the driver's dashboard to indicate that the bus is ready to proceed to the next stop,

Although energy losses during travel are very small due to a prime mover using magnetic bearings in a vacuum, electrical losses cause the flywheel to slow down overnight when the bus is garaged. The likely morning start-up procedure would be to speed the flywheel to its designed maximum speed and check it with a device, which is best described as an electronic stethoscope. Meanwhile the driver and the bus control system are instructed with the day's task.

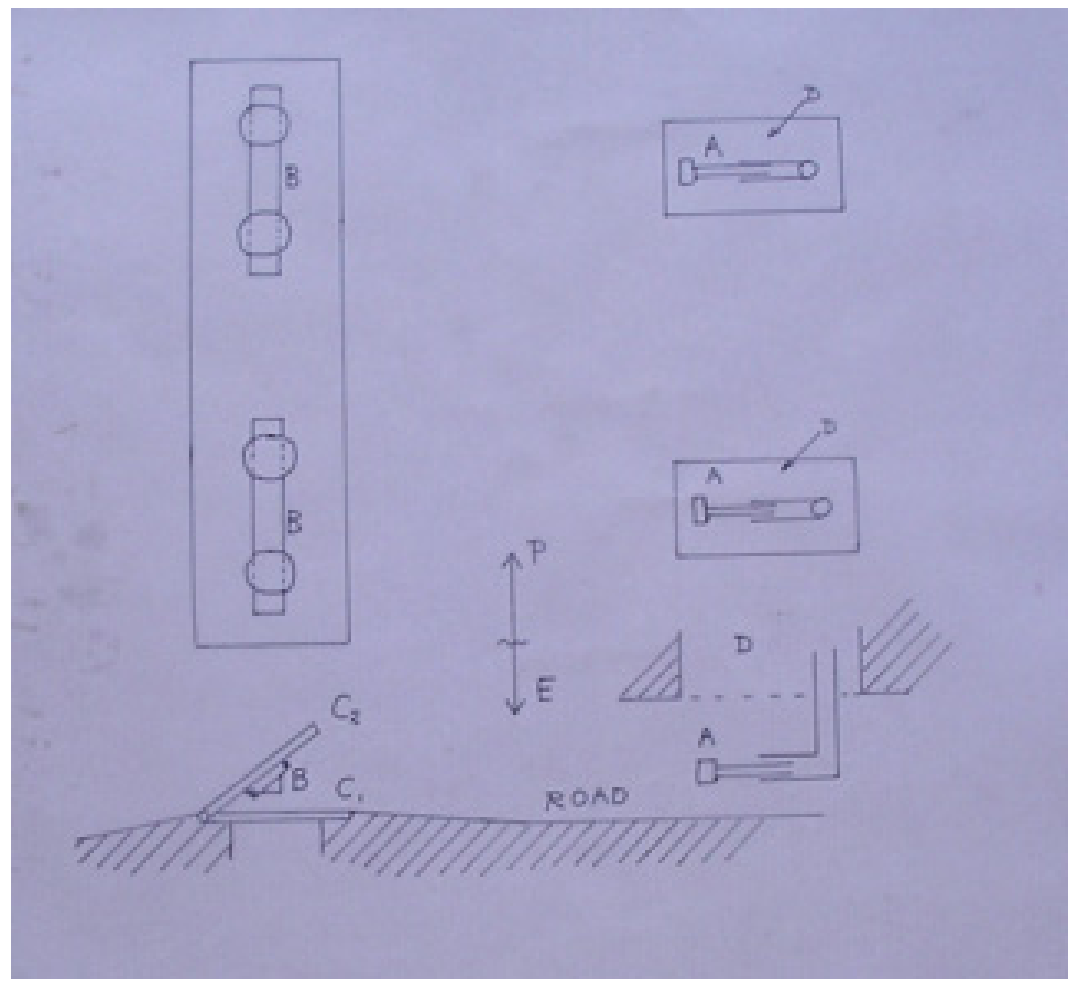

Figure 4: One version of a flywheel energising point at a bus stop. In climates requiring air-conditioning this charging point would also be used for this purpose. $\mathrm{A}=$ electrical contents on bus; $\mathrm{B}=$ electrical contacts in road; $\mathrm{C}=$ cover plate for $\mathrm{B}$; $\mathrm{D}=$ protective cavity in bus; $\mathrm{P}=$ plan view; $\mathrm{E}=$ elevation. 
There are many other factors to consider in this outlined design, which is quite complicated, such as coping with system failures. A relatively small (100kg. $600 \mathrm{~mm}$. diameter, $3 \mathrm{~kW} . \mathrm{hr}$ ) composite flywheel design would be close to optimum in most applications These details are best covered by accessing a discussion group using ref. [35] which is a restricted website. Delegates at this conference and the conference of ref. [30] can access this site by email to obtain passwords. Other readers may be able to obtain passwords by referring to refs [11] and [12] in reference [30] for the password-accessing email address.

Examples of factors, which need consideration in depth include:

a) Should more than one flywheel be used in each bus? For example, vehicle stability can be improved using two contra-rotating flywheels.

b) Regenerative braking seems essential but this raises the question of how best to achieve this? Today's luxury-class vehicles use ultracapacitors for this task.

c) It is expected that the stator of the motor/generator in the flywheel housing (fig 2) will need an external cooling circuit. The design of this does not appear to present significant problems.

d) Should the ability to include the facilities described in ref [22] be included in the design?

e) There is a sound case for adapting the final design for world markets and future needs and improvements. Although a flywheel prime mover is a complicated system with its power electronics [36], it is well-suited to modern automated mass-production manufacturing techniques. These can be exploited to keep unit production costs low if the market is large enough. Applying such marketing skills in design and sales indicates the need for project development to be best handled by major global corporations. It is not enough to use simplified data in design such as the assumption that a bus needs, say $2.5 \mathrm{~kW} \mathrm{hr} / \mathrm{km}$ travelled. Vehicles may be articulated, doubledecked or used on flat or hilly terrain or in inner city or suburban areas. A small range of energy options for the flywheel prime mover is needed.

What are also needed are a few basic designs, which can be adapted for any location in the world. For example, the energy consumed by air conditioning is a major factor in most present-day public transport. The flywheel-energised future buses envisaged for Sydney and Brisbane can dispense with air-conditioning completely by simply using sliding windows. However, such a bus could not be used in the climate of Ekaterinburg. It seems that simple adaptation of the bus entrance/exit and using an air conditioner, which only operated while the bus is stationary while charging the flywheel could suffice. Thus with sensible design we can conclude that the same basic vehicle can be used in Brisbane or Ekaterinburg with only a few necessary adaptations for local conditions. 


\section{References}

[1] Casti, J., X-Events: The Collapse of Everything, Harper-Collins: New York, pp. 180-194, 2012.

[2] Aleklett, K., Peeking at Peak Oil, Springer: New York, pp.300-305, 2012.

[3] Deffeyes, K.S., Hubbert's Peak: The impending world oil shortage, Princeton University Press, p. 176, 2008.

[4] Bardi, U., The limits to growth revisited: Springer briefs in energy analysis, Springer: Dordrecht, pp. 1-127, 2011.

[5] Wight, W. \& Newman, P., Petroleum depletion scenarios for Australian cities, Australian Planner, 47(4), pp. 232-242, 2010.

[6] Hicks, B.\& Nelder, C., Profit from the peak: the end of oil and the greatest investment event of the century, Wiley: Hoboken, p. 237, 2008.

[7] Rapier, R., Power plays: energy options in the age of Peak Oil, Springer: New York, pp. 168-169, 2012.

[8] Dunlop, I., Peak oil, climate change and global sustainability - the case for emergency action.www.ASPO-Australia.org.au

[9] Hansen, J., Storms of my grandchildren, Bloomsbury: New York, pp.162-168, 2009.

[10] ASPO (International) www.peakoil.net/

[11] ASPO (Australia) www.ASPO-australia.org.au

[12] CASSE (Centre for the advancement of the steady state economy) http:// steadystate.org

[13] Thorpe, D., Sustainable transport fuels business briefing, DoSustainability: London, pp. 1-106, 2012.

[14] Beer, T., Alternative transport fuels, Australasian Biotechnology, 19(4), pp. 20-21, 2009.

[15] Anon., The rush towards renewable oil, New Scientist, 203, pp. 61-62, 21 May 2011.

[16] Bossel, U., Lucerne fuel cell forum, (www.efcf.com/reports) Lucerne, Switzerland, 2-6 July, 2007.

[17] Larmine, J. \& Lowry, J., Electrical vehicle technology explained, (2nd edn), Wiley: New York, 2012.

[18] Schlapbach, L. \& Zuttel, A., Hydrogen storage materials for mobile applications, Nature, 414, pp. 353-358, 2002.

[19] Zhang, X., \& Mi, C., Vehicle Power Management, Springer Fachmedien: London \& Dordrecht, pp. 245-247, 2011.

[20] Weedy, B. M., Cory, B.J., Jenkins, N., Ekanayake, J. B. \& Strbac, G., Electric power systems, Wiley: Chichester (U.K.), pp. 14-15, 2012.

[21] Douglas, E., New generation flywheels, Power Engineering, 113 (5), p.14, 2009.

[22] Boothroyd, R. G., Replacing the private motor car with a more attractive public transport system. Paper 1061, General Proceedings, 12th World Conf. on Transport Research, Lisbon, 2010.

[23] Ashwath, N., Evaluating biodiesel potential of Australian native and naturalised plant species. RIRDC Publication No 10/216, December 2010. 
[24] Deuchar, M., Operate your diesel vehicle on straight used vegetable oil, (4th edn), www.vegiecars.com, Marcus@vegiecars.com, 2008.

[25] Gupta, R. B. \& Demirbas, A., Gasolene, diesel and ethanol biofuels from grasses and plants, Cambridge University Press, pp. 73-101, 2010.

[26] Bolund, B., Bernhoff, H., \& Leijon, M., Flywheel energy and power storage systems, Renewable and Sustainable Energy Reviews, 11, pp. 235-258, 2007.

[27] Ter-Gazarian, A., Energy storage for power systems, (2nd edn), Institution of Engineering and Technology: London, pp.77-83, 2011.

[28] Hook, M. \& Aleklett, K., A review on coal-to-liquid fuels and its coal consumption. Int. J. Energy Res., 34, pp. 848-864, 2010.

[29] Wright, W. \& Hearps, P. (lead authors) et al., Zero Carbon Australia Stationary Energy Plan (2nd Edn), University of Melbourne Energy Research Institute, June 2011.

[30] Boothroyd, R. G., Urban planning for emergent technologies, new life-styles and a changing environment, WIT Transactions on Ecology and the Environment, 179, pp. 93-108, 2013.

[31] Hallquist, A. M., Jerksjo, M.,Fallgren, H.,Westerlund, J. \& Sjodin, A., Particle and gaseous emissions from individual diesel and CNG buses, Atmospheric Chemistry and Physics, 13(10), pp. 5337-5350, 2013.

[32] Abrahamsson, J. \& Bernhoff, H., Magnetic bearings in kinetic energy storage systems for vehicular applications, J. Electrical Systems, 7(2), pp. 225-236, 2011.

[33] Greer, J. M., Not the future we ordered: Peak Oil, psychology and the myth of progress, Karnac Books: London, pp. 1-25, 101-120, 2013.

[34] Brune, M., Coming clean:breaking America's addiction to oil and coal, Sierra Club Books: San Francisco, pp. 103-118, 2010.

[35] Discussion facility, boothroyd.org.

[36] Schweitzer, G. \& Masien, E.H. (eds), Magnetic bearings: theory, design and application to rotating machinery, Springer: Dordrecht and Heidelburg, pp. 30-39, 229-250, 2009. 